\title{
Body composition and fat distribution during the first 2 weeks of gestation in ad lib.-fed and energy-restricted rats
}

\author{
BY ANNICA SOHLSTRÖM ${ }^{1}$, NAZMA KABIR ${ }^{1}$, AIJA SADURSKIS ${ }^{2}$ \\ AND ELISABET FORSUM ${ }^{3 *} \dagger$ \\ ${ }^{1}$ Department of Medical Nutrition, Karolinska Institute, Huddinge University Hospital F60, \\ NOVUM, S-141 86 Huddinge, Sweden \\ ${ }^{2}$ Department of Metabolic Research, Wenner-Gren Institute, University of Stockholm, \\ S-106 91 Stockholm, Sweden \\ ${ }^{3}$ Department of Nutrition, University of Uppsala, Dag Hammarskjölds väg 21, \\ S-752 37 Uppsala, Sweden
}

(Received 2 July 1992 - Revised 17 May 1993 - Accepted 28 May 1993)

\begin{abstract}
Knowledge about changes in body composition during gestation is of interest when estimating energy requirements during pregnancy, and relevant since reproduction is often surprisingly well maintained in malnourished females. Due to difficulties in conducting such studies in humans, studies in rats are of interest. Therefore, maternal retention of fat and fat-free weight was estimated in rats during the first 2 weeks of gestation and during a corresponding time period in virgin controls. Groups fed ad lib. or $70 \%$ of ad lib. intake during the 4 weeks preceding conception and during gestation were studied. Retention was estimated by comparing pregnant and virgin rats with rats killed at the time of conception. Body fat was analysed chemically and fat-free weight was body weight minus body fat. Each rat was divided into twelve to fourteen parts and the fat content of each part was analysed. Pregnant ad lib.-fed rats retained more fat and fat-free weight than did virgin ad lib.-fed controls. In the energy-restricted group the pregnant rats retained more fat-free weight while virgin rats retained slightly more fat than did pregnant rats. The difference between pregnant and virgin rats with respect to the amount of fat in the different body parts was small in both feeding groups. Thus, the statement that fat stored at specific sites in the maternal body represents an important source of energy for use during lactation was not supported. The findings suggest that pregnancy stimulates growth of the maternal body and that chronic moderate energy restriction curtails this growth.
\end{abstract}

Body composition: Energy restriction: Fat distribution: Growth: Gestation: Rat

The nutritional situation, especially the intake of energy, is important for the health of women and children (Coward et al. 1984; Gonzalez-Cossio \& Delgado, 1991). In comparison with well-nourished women, malnourished women tend to deliver children with low birth-weights which in developing countries represents an important public health problem since a low birth-weight is associated with increased infant morbidity and mortality (Gonzalez-Cossio \& Delgado, 1991), Also, the prevalence of diseases such as cardiovascular disease, cancer, diabetes and obesity tends to increase with increasing standard of living and it has been suggested (Stini, 1978; Willett, 1989) that overnutrition during early life may be a factor in the aetiology of some of these diseases. Thus, knowledge of energy needs during reproduction is important.

During reproduction the female needs extra energy from food to support various

* Present address: Department of Surgery, University of Linköping, University Hospital, S-581 85 Linköping, Sweden.

$\uparrow$ For reprints. 
physiological changes such as the demands induced by the synthesis of fetal and maternal tissue, milk production and the increase in energy metabolism. Humans as well as rats are able to reproduce surprisingly well in spite of a restricted energy intake, although in rats the offspring may be smaller and the number of pups per litter tends to decrease (Young \& Rasmussen, 1985; Sadurskis et al. 1991). Mechanisms protecting reproduction in spite of a restricted food supply are apparently present, probably to assure the survival of the species in harsh dietary situations. According to a hypothesis describing 'the fetus as a perfect parasite', the fetus is able to receive more nutrients per unit body weight than maternal tissues and will, even if the food intake of the mother is restricted, maintain normal growth whereas the mother will become progessively more depleted. Only when maternal stores are totally depleted will fetal growth be affected (Hammond, 1944). However, more recent work (Lederman \& Rosso, 1981; Sadurskis et al. 1991) indicates that a starving mother is, to some extent, able to protect her own stores at the expense of the growing fetus. Apparently, priorities between the fetal and maternal energy needs are made by the pregnant organism during starvation. Little is known about how such priorities affect maternal physiology and fetal development but it is most likely that maternal metabolism and body composition will be affected, possibly influencing the health of mother and offspring.

A pregnant woman is estimated to need a total of $335 \mathrm{MJ}$ over her non-pregnant requirements to cover the total energy cost of pregnancy (World Health Organization, 1985 ), almost $50 \%$ of which is the energy needed to retain about $4 \mathrm{~kg}$ fat. Healthy women vary considerably, however, with respect to the amount of fat retained during pregnancy (Forsum et al. 1992). In rats also, pregnancy is associated with retention of fat by the dam (Spray, 1950; Naismith et al. 1982). This maternal fat retention together with the high energy content of fat have raised questions about the biological significance of changes in the body fat content during reproduction. Thus, the retained fat is often considered to represent a store of energy to be used during late pregnancy and lactation (World Health Organization, 1985). A corollary of this statement seems to be that it should be possible to identify an optimal fat gain during pregnancy below which reproductive performance is impaired and above which the risk of obesity in the mother and/or the offspring is increased. However, Langhoff-Roos et al., 1987 were unable to identify any relationship between maternal fat gain during pregnancy and infant birthweight. Furthermore, body fat does not seem to be readily mobilized during lactation in well-nourished women (Sadurskis et al. 1988; Goldberg et al. 1991). Not even in rat dams subjected to chronic moderate energy restriction was mobilized body fat a quantitatively important source of energy during lactation, and although energy-restricted dams retained fat during pregnancy this retention was smaller than that of virgin controls (Sadurskis et al. 1991).

In studies of adipocytes from the femoral region in women, an increased activity of lipoprotein lipase (EC 3.1.1.34) during early pregnancy and an increased lipolytic activity during lactation were found (Rebuffé-Scrive et al. 1985) while parametrial rat adipocytes had an increased activity of lipoprotein lipase during early pregnancy (Hamosh et al. 1970). Thus, it was suggested that the fat retained during pregnancy is deposited at specific sites in the body serving the biological function of 'reproductive energy stores'. A study by Steingrimsdottir et al. (1980), showing that the fat retained during gestation in the rat is unevenly distributed among body depots, seems to support this suggestion. However, apart from a study by Naismith et al. (1982) reporting that, in rats, $36 \%$ of the pregnancyinduced fat retention was placed under the skin, $29 \%$ in the ovarian and lumbar regions and $34 \%$ in the carcass, systematic studies of the potential of pregnancy to induce fat retention at specific sites of the female rat body are lacking.

Gestation is also associated with maternal retention of fat-free weight (Spray, 1950; 
Hytten, 1980). An average healthy woman retains about $4 \mathrm{~kg}$ fat-free weight if the product of conception is disregarded (Hytten, 1980). In fact, some results suggest that birth-weight in humans is related to the size of the maternal fat-free body rather than to the amount of fat retained during pregnancy (Briend, 1985; Langhoff-Roos et al. 1987). Furthermore, in Swedish women the total content of body $\mathrm{K}$ changed during early pregnancy and the size of this change was related to the size of the baby (Forsum et al. 1988; N. Kabir, A. Sadurskis and E. Forsum, unpublished results). This is noteworthy since the body $\mathrm{K}$ content of women during early pregnancy is related to the maternal fat-free weight.

The present study addresses the following questions: (1) to what extent does pregnancy in rats induce retention of fat and fat-free weight of the maternal body? (2) how is the pregnancy-induced retention of fat and fat-free weight affected by energy restriction? (3) what is the effect of pregnancy on the amount of fat retained in different parts of the rat body? (4) how are these amounts affected by chronic energy restriction?

\section{MATERIALS AND METHODS \\ Experimental design and animal handling}

The study is outlined in Fig. 1. Virgin female Sprague-Dawley rats ( $n$ 46; Alab, Stockholm, Sweden), 55-60 d old, were divided into two groups with body weight 193 (SD 8) g on day 1 of the experiment. One group ( $n$ 21) had free access to food (100-group or ad lib.-fed) while the other ( $n$ 25) was offered $70 \%$ of the intake of ad lib.-fed rats (70group or energy-restricted). After $28 \mathrm{~d}$ one subgroup of rats from each dietary group was formed. These rats were not mated (virgin rats) and were followed during a reference period of $14 \mathrm{~d}$ starting on day 32 of the experiment and ending when they were killed on day 46 of the experiment. The other rats were mated as follows: $30 \mathrm{~min}$ after the end of the light period each female was placed with a male in a cage in a dimly lit room. If mating took place within 20 min the animals were left to mate several times. If the animals did not mate, another attempt was made the next evening. Between days 28 and 36 of the experiment fourteen rats from each dietary group mated. Two rats from the 100-group and six from the 70-group did not mate and were omitted from the study. The day after mating was designated day 1 of gestation and on this day subgroups from both dietary groups were formed and killed (conception rats). The rats remaining in the study were killed $14 \mathrm{~d}$ after the day of mating, i.e. at the end of the gestation period. Five rats in each dietary group contained fetuses visible upon dissection (pregnant rats). The remaining rats (three from the 100-group and four from the 70-group) were omitted from the study. The period between day 1 of the experiment and the day of mating (conception and pregnant rats) or day 32 of the experiment (virgin rats) was the adaptation period. Throughout the experiment rats were weighed three times weekly, on days when subgroups were formed and on the day of killing. Virgin rats were also weighed on day 32 of the experiment. When virgin and conception subgroups were formed rats were selected with an average body weight as similar as possible to the average body weight of all other rats in the experiment with the same physiological state and dietary treatment.

The food intake of the ad lib.-fed rats was monitored daily to the nearest $0 \cdot 1 \mathrm{~g}$. Each day during the adaptation period, energy-restricted rats were served $70 \%$ of the average food intake of all non-pregnant ad lib.-fed rats on the previous day. Each day during the gestation period, energy-restricted pregnant rats were served $70 \%$ of the average food intake of the first three mated ad lib.-fed rats on the corresponding day of gestation. Each day during the reference period, virgin energy-restricted rats were served $70 \%$ of the average intake of ad lib.-fed virgin rats on the previous day. Energy-restricted rats always consumed all the food they were offered. The diet was a modified version of AIN-76 

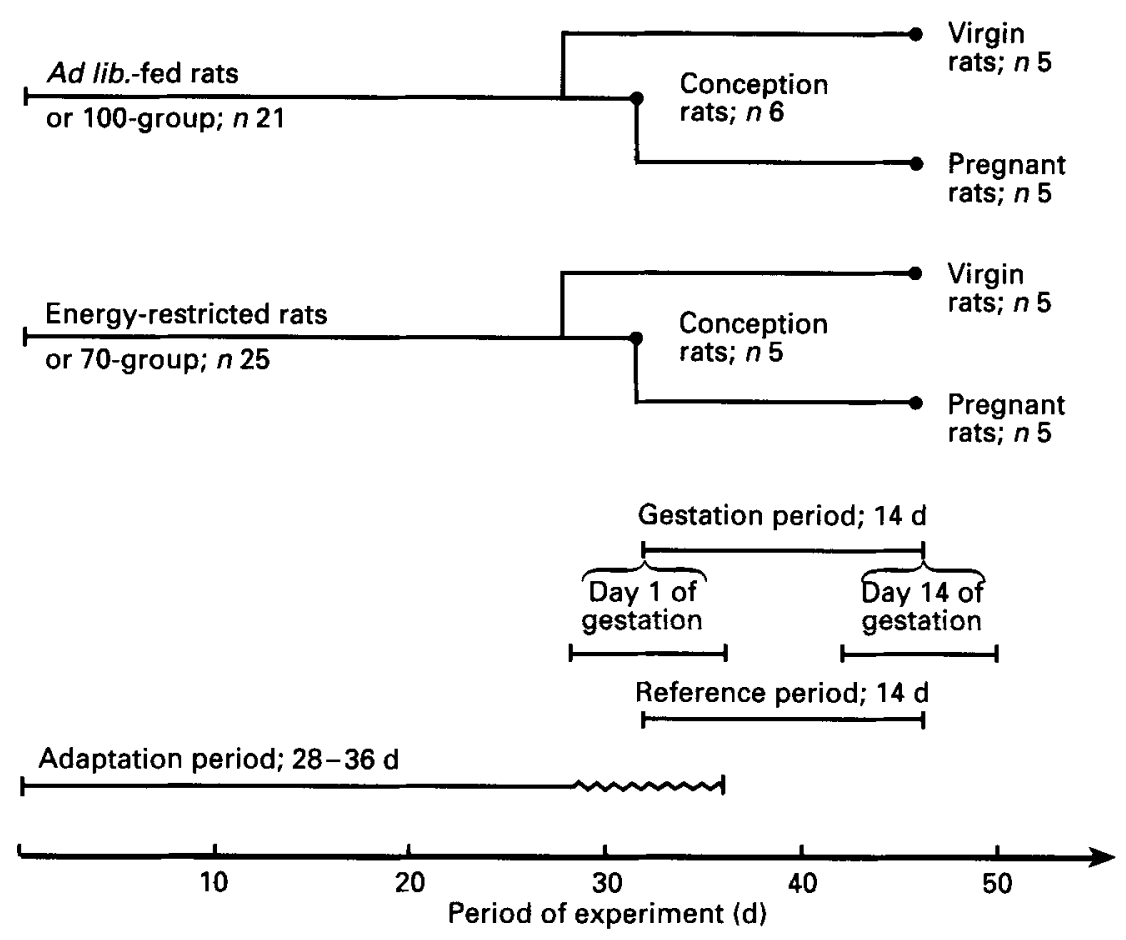

Fig. 1. Outline of experimental design.

(American Institute of Nutrition, 1977; Sadurskis et al. 1991) containing $200 \mathrm{~g}$ protein $/ \mathrm{kg}$, with part of the sugar replaced by starch and with the levels of vitamins and minerals increased by 50 and $40 \%$ respectively. The animals were kept individually on wood shavings in plastic cages $(250 \times 400 \mathrm{~mm})$ in a room with a $12 \mathrm{~h}$ light-12 h dark cycle and a temperature of $21^{\circ}$, and with free access to tap water.

\section{Dissection}

The rats were killed by $\mathrm{CO}_{2}$ inhalation, weighed and divided into the following parts: the subscapular skin, a rectangle on the back of the animal defined by transversal lines drawn just cranially to the forelegs and just caudally to the ribs and connected with two longitudinal lines drawn as lateral as possible; the abdominal skin, defined as a rectangle on the ventral trunk confined by transversal lines, one between the forelegs at the level of the caudal axillar fold, one just cranially of the urethra, and by longitudinal lines just laterally to the nipples; the rest of skin was the skin left after removing the abdominal and subscapular skin, although the skin above ears and mouth and on the paws was left with the rest of the body (see p. 321). The adipose tissue, the fibrous connective tissue and the fur were included in the skin parts; the perivesicular region was defined as the cluster of adipose tissue located ventrally and laterally to the urinary bladder; the gastrointestinal tract included omentum, stomach, spleen, small and large intestine, rectum and the adipose tissue attached to these organs. It was cut cranially at the cardiac region of the stomach and caudally at the distal end of the rectum; the internal genital region, cut just cranially to the ovaries and at the cervix of the uterus as caudal as possible, included the uterus and the ovaries as well as the adipose tissue attached; the perirenal region was the adipose tissue around the kidneys; the retroperitoneal region was the two patches of adipose tissue visible on each side of the vertebral column after removing the gastrointestinal tract; the liver 
constituted a discrete section; the hind legs and the forelegs were separated from the body by cutting through the shoulder and hip joints respectively; the rest of the body was the remaining parts of the rat; the fetuses (complete individuals) and the placentas (complete placentas with amniotic fluid and membranes) were collected from pregnant rats.

\section{Fat and fat-free weight in parts and total bodies of rats}

All parts of the rat bodies were weighed after dissection and then kept at $-20^{\circ}$. The rest of the body was autoclaved $\left(120^{\circ}, 20 \mathrm{~min}\right)$, weighed, homogenized (Waring blender; Tecnora, Malmö, Sweden), freeze-dried, reweighed and ground to a powder. The liver, forelegs, hind legs, the skin parts and the gastrointestinal tract were autoclaved as described previously, weighed, freeze-dried, reweighed and ground to a powder. The fetuses, placentas, internal genital region and the perivesicular, perirenal and retroperitoneal regions were lyophilized and weighed. The fat content of powder and freeze-dried organs was determined by extraction with light petroleum (b.p. $40-60^{\circ}$, Soxtec System Ht, Höganäs, Sweden). Each sample was extracted to complete recovery of fat (two or three times). The fat content of the total rat body was the sum of the fat contents in all body parts. The fat-free weight of the total rat body was the weight of the rat minus its fat content.

\section{Retention of fat and fat-free weight}

The amounts of fat (or fat-free weight) retained during the gestation or reference periods respectively, for pregnant and virgin rats, were calculated as the average amount of fat (or fat-free weight) in the total body, or in its different parts, minus the corresponding values for conception rats.

\section{Statistical treatment}

For comparisons involving more than two groups, two-way analysis of variance (Snedecor \& Cochran, 1973) was used with dietary treatment ( $a d$ lib. feeding or energy restriction) and physiological state (conception, pregnant or virgin) as the two fixed components of variation. If a significant difference $(P<0.05)$ between physiological states was found this was identified by calculating the least significant difference (Snedecor \& Cochran, 1973). If significant interaction was found $(P<0.05)$ results were tested for simple main effects (Kirk, 1966). When two means were compared, the Student's $t$ test, paired or unpaired (Armitage, 1971) was used. Linear regression was calculated as described by Armitage (1971).

\section{RESULTS}

\section{Growth, food intake and food efficiency}

Table 1 shows the body weight, weight gain, food intake and food efficiency during the adaptation, gestation and reference periods for the six subgroups of rats. During the adaptation period each ad lib.-fed subgroup gained, on average, about $50 \mathrm{~g}$ body weight, while energy-restricted subgroups tended to lose weight. However, during the gestation and reference periods all subgroups gained weight, although ad lib.-fed subgroups gained significantly more weight than the corresponding energy-restricted subgroups. Within each dietary treatment, pregnant rats gained significantly more weight than did virgin rats. $A d$ lib.-fed pregnant rats gained 46 (SD 3) g during the gestation period and most of this gain 41 (SD 3) g represented gain in the maternal body. The corresponding values for energyrestricted pregnant rats were 33 (SD 2) and 30 (SD 2) g respectively. The amount of weight gained in the maternal body was significantly different between these two groups $(P<0.001)$.

During the adaptation period the food intake of the three ad lib.-fed subgroups was 


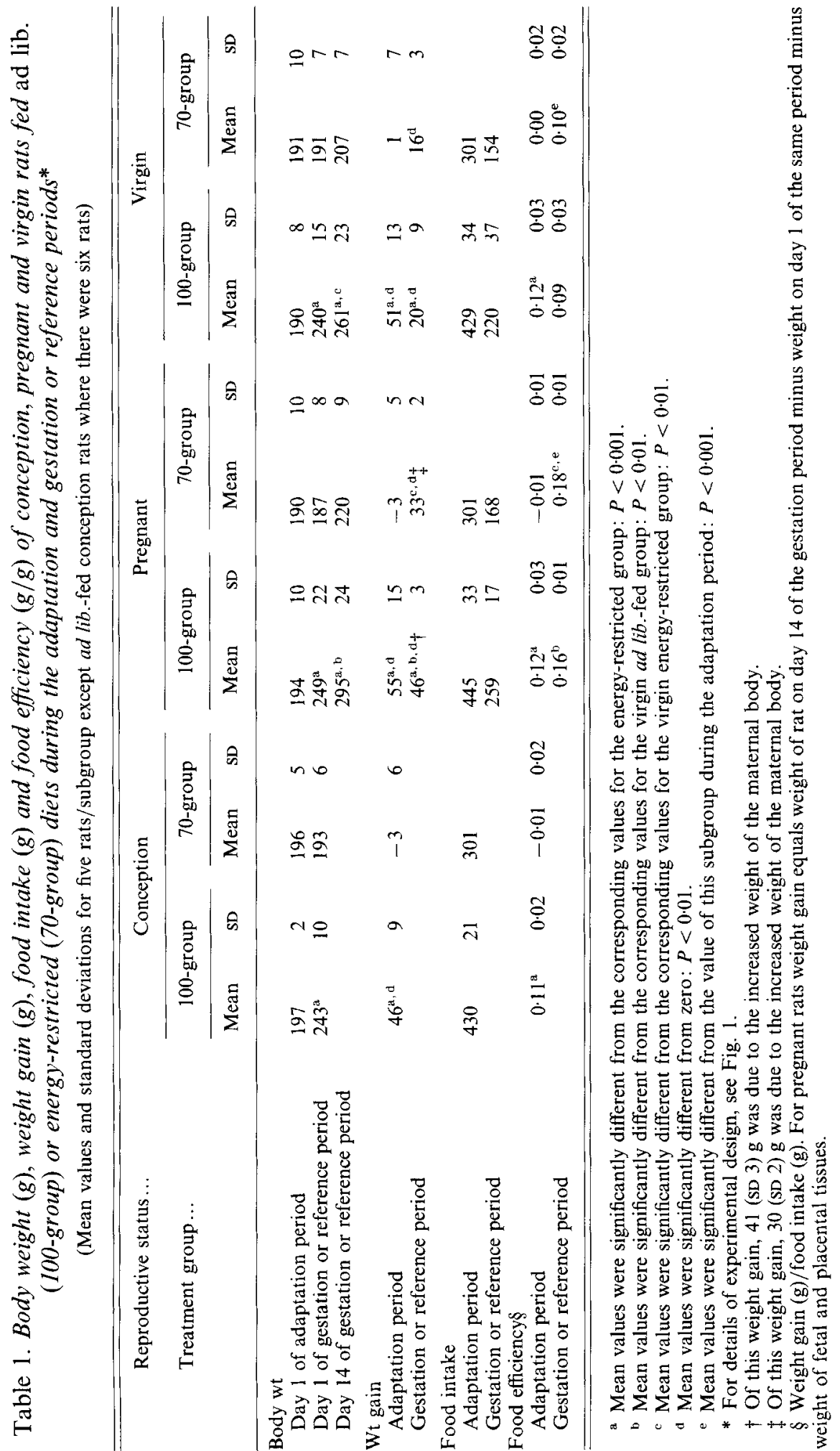


similar. During the gestation and reference periods, pregnant ad lib.-fed rats consumed slightly but not significantly more food than did virgin ad lib.-fed rats. During the adaptation period, energy-restricted subgroups consumed $70 \%$ (conception), $68 \%$ (pregnant) and $70 \%$ (virgin) of the average intake of rats in the corresponding ad lib.-fed subgroups. During the gestation or reference periods these values were $65 \%$ (pregnant) and $70 \%$ (virgin). The food efficiency (weight gain $(\mathrm{g}) /$ food intake $(\mathrm{g})$ ) was similar during the adaptation period for all ad lib.-fed subgroups and, for each, it was significantly higher than for the corresponding energy-restricted subgroup. The food efficiency of pregnant rats during the gestation period, ad lib.-fed as well as energy-restricted, was significantly higher than that for their virgin counterparts during the reference period. However, energyrestricted rats, pregnant as well as virgin, had significantly higher food efficiency during the gestation or reference period than during the adaptation period.

\section{Fat-free weight and fat in the total rat body}

Fig. 2 shows retention of fat and fat-free weight during the gestation period for pregnant rats and during the reference period for virgin rats in the ad lib.-fed (Fig. 2(a)) and energyrestricted (Fig. 2(b)) groups respectively. In the ad lib.-fed group, virgin as well as pregnant rats retained fat-free weight as well as fat. Pregnant rats retained $41.7 \mathrm{~g}$ fat-free weight and $10.3 \mathrm{~g}$ fat while the corresponding values for virgin rats were 13.0 and $5.0 \mathrm{~g}$. Thus, in this dietary group, pregnant rats retained more fat-free weight and fat than did virgin rats. Also in the energy-restricted group, pregnant as well as virgin rats retained fat and fat-free weight. With respect to fat-free weight the former retained as much as $19.2 \mathrm{~g}$ and the latter only $1.3 \mathrm{~g}$, while retention of fat was slightly higher for virgin $(12.6 \mathrm{~g})$ than for pregnant rats $(9 \cdot 2 \mathrm{~g})$. Only a small part, 11 and $15 \%$ in the ad lib.-fed and energy-restricted groups respectively of the total amount of fat-free weight retained by pregnant rats, was due to fetal and placental tissue.

Table 2 shows the body weight, fat-free and fat weight as well as fat concentration of the complete rat bodies. $A d$ lib.-fed subgroups were significantly heavier and contained significantly more fat-free and fat weight than did their corresponding energy-restricted counterparts. $A d$ lib.-fed conception and pregnant rats also had a significantly higher concentration of fat in their bodies than had the corresponding energy-restricted subgroups. Virgin energy-restricted rats, however, had a higher concentration of fat in the body than virgin ad lib.-fed rats, but this difference was not significant.

Pregnant rats from both feeding groups were significantly heavier and contained significantly more fat-free and fat weight than did the corresponding conception subgroups. Similar observations were made for virgin rats, although the differences between virgin and conception rats were not always significant. In none of the dietary groups was the concentration of fat in the body significantly different between pregnant and conception rats, while virgin rats from both dietary groups had a significantly higher concentration of body fat than had the corresponding conception subgroups. For ad lib.-fed rats this difference was only $10 \mathrm{~g}$ fat $/ \mathrm{kg}$ body weight while it was as much as $60 \mathrm{~g}$ fat $/ \mathrm{kg}$ body weight in the energy-restricted group.

Pregnant rats from both dietary groups were significantly heavier and contained significantly more fat-free weight than did the corresponding virgin subgroups. Ad lib.-fed pregnant rats contained more (but not significantly) fat than did ad lib.-fed virgin rats but the fat concentration of these two subgroups was the same $(140 \mathrm{~g} / \mathrm{kg}$ body weight). Energyrestricted pregnant rats contained less fat, in $\mathrm{g}$ as well as proportionally (in $\mathrm{g} / \mathrm{kg}$ body weight), than energy-restricted virgin rats but these differences were not significant. 

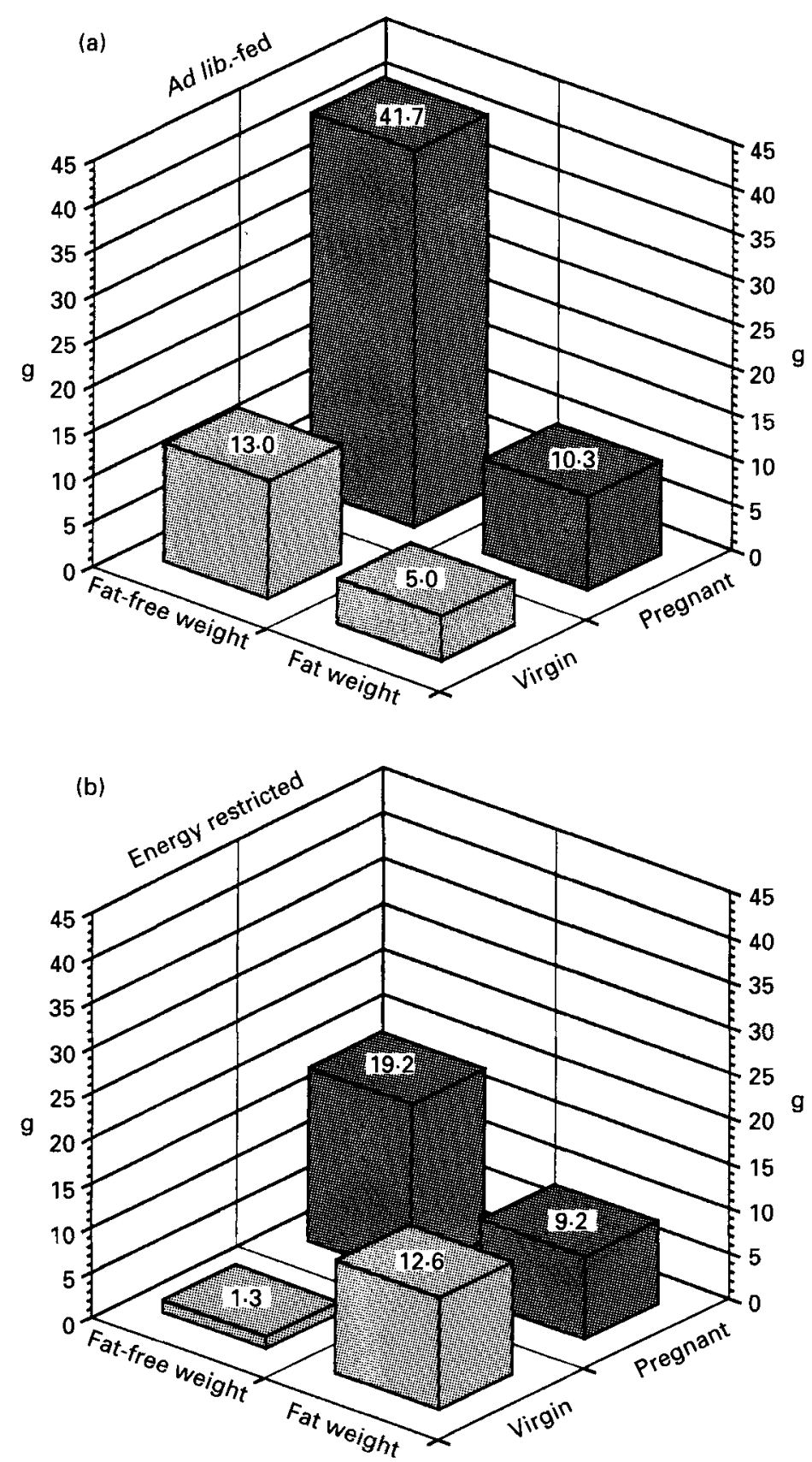

Fig. 2. Retention of fat weight ( $\mathrm{g}$ ) and fat-free weight $(\mathrm{g})$ in the total body of (a) ad lib.-fed rats and (b) energyrestricted rats during the gestation period for pregnant rats (average for pregnant rats minus average for conception rats) and during the reference period for virgin rats (average for virgin rats minus average for conception rats). For details of procedures, see pp. 319-321.

Fat in parts of the rat body

Fig. 3 shows the retention of fat in the different parts of the body during the gestation period for pregnant rats and during the reference period for virgin rats in the ad lib.-fed (Fig. 3(a)) and energy-restricted (Fig. 3(b)) groups respectively. In the ad lib.-fed group 


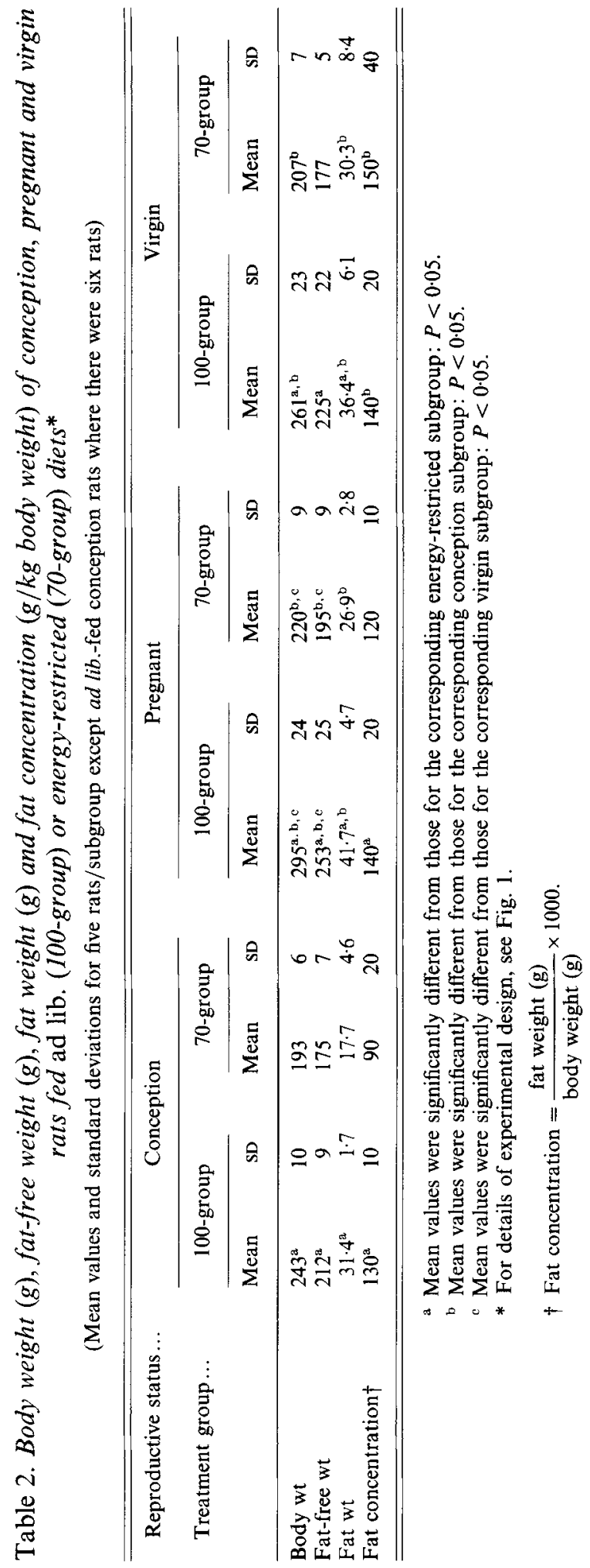




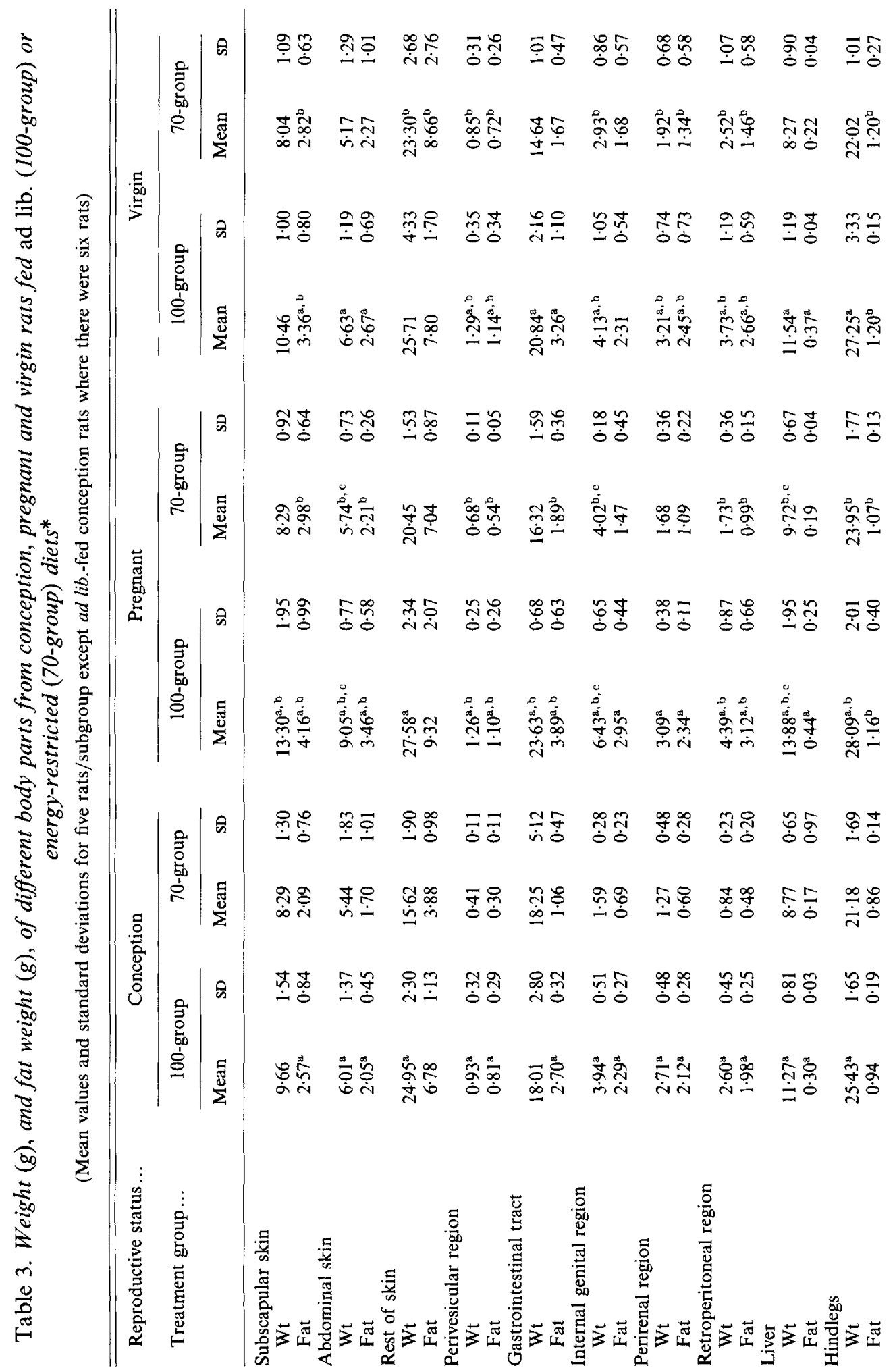




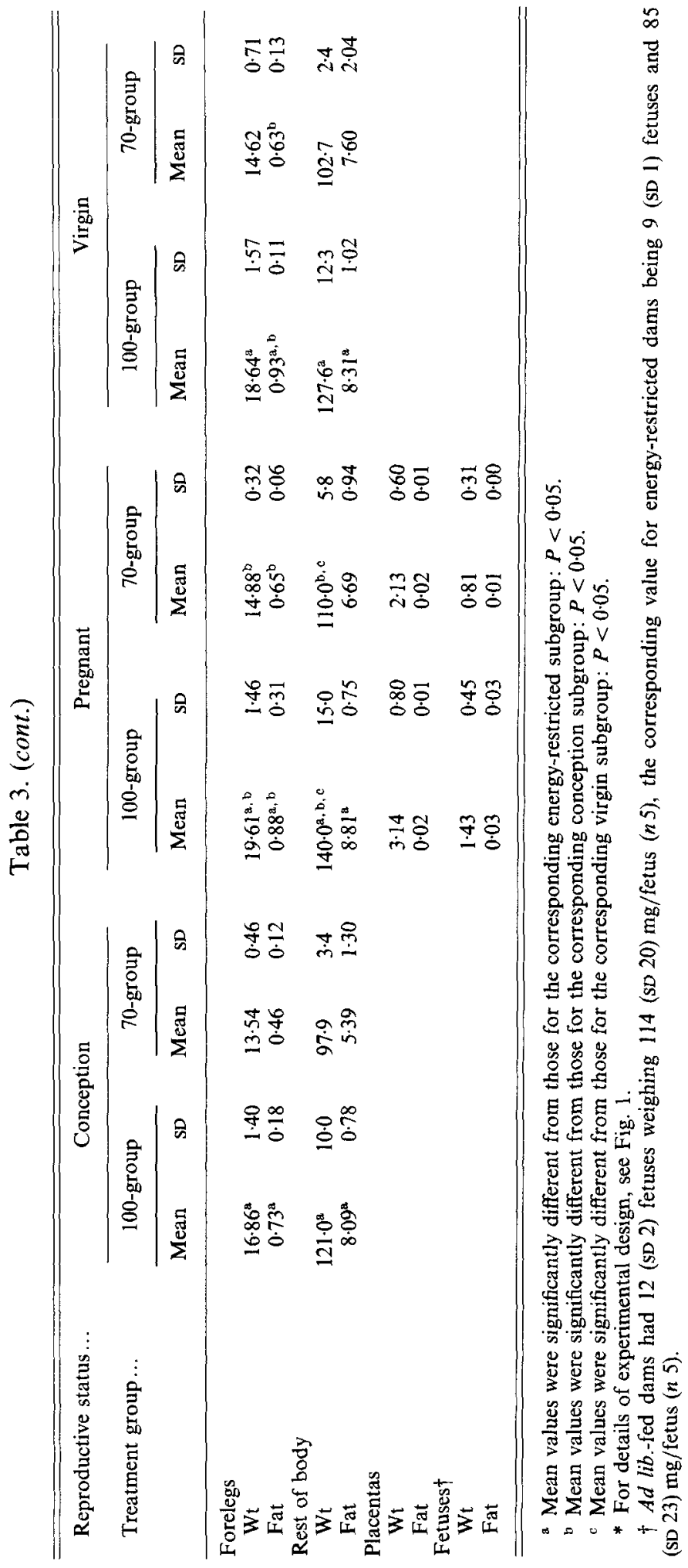



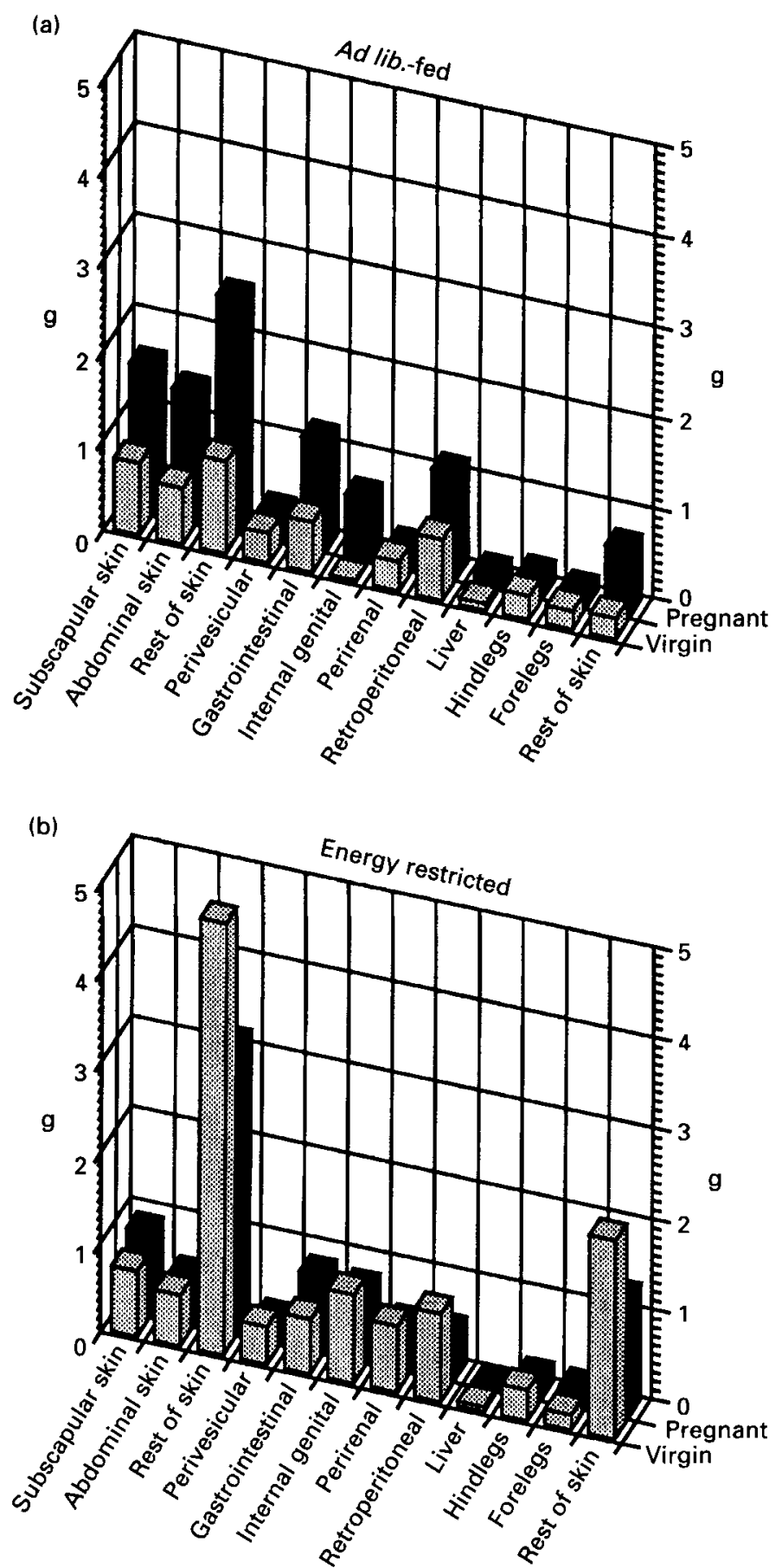

Fig. 3. Retention of fat weight (g) in different parts of the body of (a) ad lib.-fed rats and (b) energy-restricted rats during the gestation period for pregnant rats (average for pregnant rats minus average for conception rats) and during the reference period for virgin rats (average for virgin rats minus average for conception rats). For details of procedures, see pp. 319-321. 


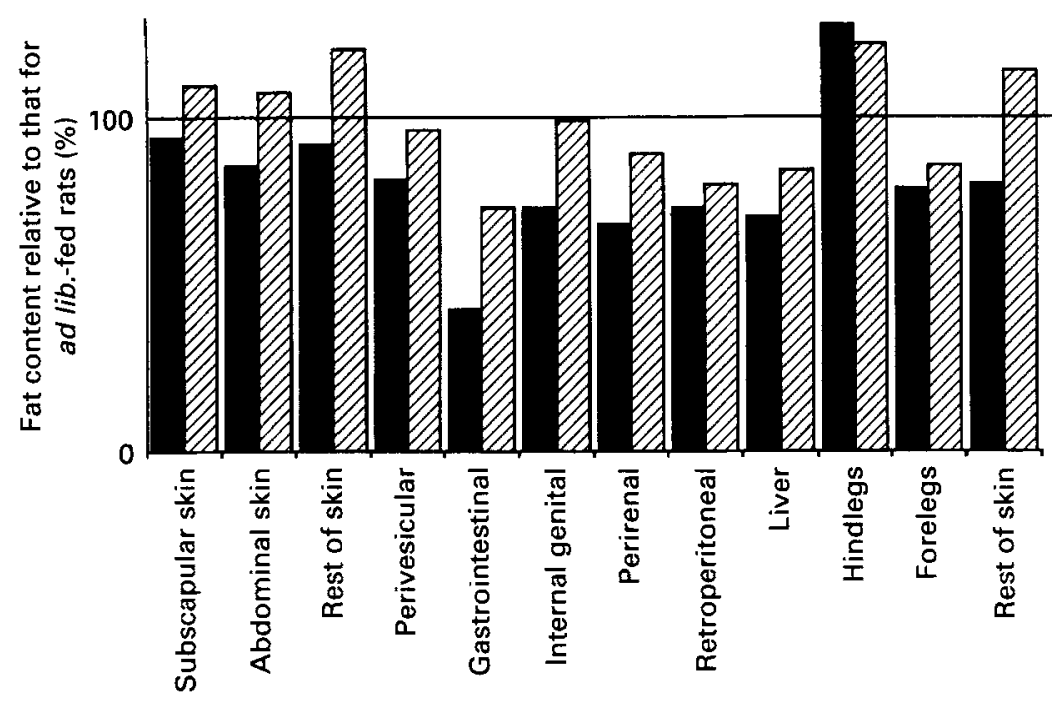

Fig. 4. Average concentration of fat $(\mathrm{g} / \mathrm{g})$ in body parts of energy-restricted rats relative to corresponding values for ad lib.-fed rats (\%). (ם), Conception rats; (罝), virgin rats. For details of procedures, see pp. 319-321.

pregnant as well as virgin rats retained some fat in all parts of the body, although the values for pregnant rats tended to be the highest. As is evident from Fig. 3(a), the main part of the pregnancy-induced fat retention was distributed between the three skin parts, the gastrointestinal, internal genital and retroperitoneal regions, as well as the rest of the body. In the energy-restricted group, however, pregnant rats retained less fat in most of the previously-mentioned body parts than did virgin rats, the exceptions being the subscapular skin and the gastrointestinal tract where pregnant rats retained slightly more fat than did virgin rats.

Table 3 shows the weight and fat weight of all parts of the body from the six subgroups of rats in the study. Pregnant and virgin rats from both feeding groups contained significantly more fat than the corresponding conception rats in the following body parts: subscapular skin, retroperitoneal and perivesicular parts, as well as in hindlegs and forelegs. Pregnant rats from both feeding groups also contained significantly more fat than the corresponding conception rats in the gastrointestinal tract and in the abdominal skin, while virgin rats from both feeding groups contained significantly more fat than the corresponding conception rats in the perirenal region. For none of the feeding groups did pregnant rats contain significantly more fat than virgin rats in any of the body parts investigated. The same observation was made for most parts of the body if the fat content was expressed as a proportion of the weight of each particular part.

The previously mentioned results indicate that energy-restricted virgin rats retained comparatively large amounts of fat during the reference period since energy-restricted conception rats contained less fat than any other group while energy-restricted virgin rats had a comparatively high fat content. These findings suggest that energy-restricted virgin rats repleted their fat stores during the reference period. Fig. 4 shows the average concentration of fat in body parts of conception and virgin energy-restricted rats, as a percentage of the corresponding values for ad lib.-fed rats, thus illustrating the relative fat content in each body part of energy-restricted rats before and after the reference period. Apparently, energy-restricted conception rats had a lower concentration of fat than their ad lib.-fed counterparts in almost all parts of the body. Energy-restricted virgin rats, on the other hand, had a higher concentration of fat than ad lib.-fed virgin rats in several body 
parts, for example, in the skin parts and in the 'rest of the body'. When the average concentration of fat in body parts of energy-restricted rats was expressed as a percentage of the corresponding value for ad lib.-fed rats, higher values were obtained for virgin than for conception rats for eleven of the twelve parts investigated.

\section{DISCUSSION}

Creating energy restriction by limiting food intake may give rise to a shortage of specific nutrients. Therefore, the contents of minerals and vitamins in the experimental diet were increased to ensure an adequate intake in energy-restricted rats. Regarding protein intake, calculations in a paper reporting a study of similar design, experimental diet and level of energy restriction as the present one, showed a dietary protein content of $200 \mathrm{~g} / \mathrm{kg}$ to be adequate even for the pregnant energy-restricted group (Sadurskis et al. 1991). Consequently, the dietary treatment of the energy-restricted rats in the present study could be regarded as a pure energy restriction with no risk of nutrient deficiency. It should also be noted that the weight gain and food intake of the rats in the present study were similar to corresponding values obtained previously (Sadurskis et al. 1991).

In studies on rats Knopp et al. (1973) identified metabolic changes favouring fat retention during approximately the first 2 weeks of gestation, while they considered that lipid stores do not increase, and may even decrease, during the last week of rat pregnancy. $\mathrm{N}$ metabolism has been suggested to follow a similar pattern (Anderson et al. 1980). Thus, in the present study changes in body composition were investigated during the first 2 weeks of gestation. The assumption that pregnant rats, at least of the strain used in our experiments, retain fat mainly during the first 2 weeks of gestation is also supported by the following comparison; ad lib.-fed pregnant rats in the present study contained $41.7 \mathrm{~g}$ $(140 \mathrm{~g} / \mathrm{kg})$ body fat while, in a previous study, ad lib.-fed rats killed immediately after delivering their litters contained $41.6 \mathrm{~g}(146 \mathrm{~g} / \mathrm{kg})$ fat (Sadurskis et al. 1991). Furthermore, comparing the amount of fat retained by our ad lib.-fed rats in response to the first 2 weeks of pregnancy $(5.3 \mathrm{~g})$ with the value $7.6 \mathrm{~g}$, representing the amount of fat retained in response to the complete pregnancy by the rats studied by Naismith et al. (1982), provides further support for the statement that a considerable proportion of the fat retained by rats in response to pregnancy is retained during the first 2 gestational weeks.

The variances of the means presented in Tables 2 and 3 were in several cases significantly different. Attempts to eliminate these differences by mathematical transformations were not successful. The data were nevertheless analysed by analysis of variance since no systematic pattern was evident with respect to the size of the variances. Analysis of the data by Student's $t$ test gave essentially the same results.

Energy-restricted virgin rats gained almost no fat-free weight during the reference period while instead their fat stores were repleted. These observations may be explained in the following way: during the adaptation period a depletion of body fat stores occurs while the metabolism of the animal adapts, the consequence being retardation of growth during the reference period. This results in decreased energy needs, thereby saving energy for the retention of body fat. However, the biological purpose of this fat retention, which could be described as a repletion and possibly also as a redistribution of body fat, is unclear. Similar observations with respect to fat retention in response to prolonged moderate energy restriction have been made previously (Sadurskis et al. 1991). It is of interest to note that fat retention was partly offset if the energy-restricted rat became pregnant when instead the retention of fat-free weight was stimulated.

Our observations demonstrate that pregnancy stimulates a retention of fat and fat-free weight by the maternal rat body. The fat retained in response to pregnancy seems to be 
evenly distributed in the maternal body, and in none of the dietary groups was there any significant difference between pregnant and virgin rats with respect to the amount of fat in any of the body parts studied. In the ad lib.-fed group pregnant rats retained $5 \cdot 3 \mathrm{~g}$ fat more than virgin rats which is equivalent to only about $40 \%$ of the energy content of the milk produced by a dam during $1 \mathrm{~d}$ at peak lactation. Thus, we were not able to identify any fat depots that could possibly serve as energy stores of quantitative significance later in the reproductive cycle. Furthermore, only $28 \%$ of the increased energy intake by ad lib.-fed pregnant rats during the first 2 weeks of gestation was used for retention of body fat. These findings are in accordance with our earlier observations (Sadurskis et al. 1991) that only a minor part of the energy cost of lactation was covered by mobilized body fat. Thus, our observations question the statement by Naismith et al. (1982) that energy from body stores makes a major contribution to the energy cost of lactation in rats. On the basis of these results we conclude that, in rats, an important physiological effect of pregnancy is to stimulate a general growth of the maternal body and that the retention of fat associated with pregnancy to a large extent seems to be a consequence of this growth rather than the result of a physiological tendency to store fat as a reserve of energy for use later in the reproductive cycle. The statement that pregnancy has a general growth-stimulating effect on the maternal body is also supported by observations on growth and food efficiency during pregnancy, as shown in Table 1.

One purpose of the present experiment was to study how chronic moderate energy restriction interacted with the effects of pregnancy on body composition and fat distribution. Interpreting the results in the context of the effects of pregnancy and of prolonged moderate energy restriction on body composition, as discussed previously, suggests the following conclusion: the most striking effect of this kind of energy restriction seems to be curtailing the growth of the maternal body associated with pregnancy in rats. The amount of fat retained by energy-restricted pregnant rats, as well as the distribution of this fat in the maternal body, could probably be regarded as the combined result of the fat gain associated with the growth induced by pregnancy and the repletion of body fat stores occurring in response to the metabolic changes induced by prolonged energy restriction.

Energy-restricted pregnant dams had on average nine fetuses with a mean weight of $85 \mathrm{mg}$, while the corresponding values for ad lib.-fed pregnant dams were twelve fetuses and $114 \mathrm{mg}$. Thus, dams in the energy-restricted group tended to have fewer and lighter fetuses which agrees with earlier reports (Young \& Rasmussen, 1985; Sadurskis et al. 1991). Thus, our results tend to support the view that the mother is to some extent able to protect her own tissues at the expense of fetal growth. The factors determining fetal growth as well as the proportion of dietary energy directed to each growing fetus are, however, still unknown. In an earlier publication (Sadurskis et al. 1991) it was suggested that the small progeny of chronically malnourished females represents an adaptive strategy to an environment in which the availability of food is limited, the implication being that the nutritional situation of the mother interferes with the mechanisms regulating fetal growth. A link between the factors determining the partitioning of dietary energy between maternal and fetal needs and factors involved in fetal growth regulation was also suggested. In the present study we found evidence for the statement that, in rats, maternal energy intake is related to the growth of the maternal body at the beginning of pregnancy. A significant linear relationship between the net maternal weight gain during the gestation period and the number of fetuses was also observed, the coefficient of correlation being 0.83 ( $n 10$, $P<0.01$ ). We conclude, therefore, that energy intake, fetal growth and growth of the maternal body are related to each other during early pregnancy in rats.

In summary, the present study shows that pregnancy in rats stimulates the retention of 
body weight, fat as well as fat-free weight, by the dam. Fat retention seems to be largely explained on the basis of the expected fat content in the tissues gained rather than by a physiological tendency to store fat in depots for future needs. The results also show that chronic moderate energy restriction depressed the stimulating effect of pregnancy on maternal weight gain, and finally they suggest that the amount of fat retained by energyrestricted pregnant rats, as well as its distribution in the body, may be influenced by previous maternal dietary experience.

The authors' thanks are due to Dr F. Reinholt for guidance regarding dissection of rats, to $\mathrm{Mr} \mathrm{O}$. Belter for help with the illustrations and to S. Sadhegi for analysis of rat bodies. This study was supported by grants from the Swedish Medical Research Council (project no. 08693), the Swedish Council for Forestry and Agricultural Research, the Karolinska Institute Funds for Research, the General Maternity Hospital Foundation, M. Bergvalls Foundation and 'Expressen' Prenatal Research Foundation.

\section{REFERENCES}

American Institute of Nutrition (1977). Report of the American Institute of Nutrition ad hoc Committee on Standards for Nutrition Studies. Journal of Nutrition 107, 1340-1348.

Anderson, G. D., Ahokas, R. A., Lipshitz, J. \& Dilts, P. V. (1980). Effect of maternal dietary restriction during pregnancy on maternal weight gain and fetal birth weight in the rat. Journal of Nutrition 110, 883-890.

Armitage, P. (1971). Statistical Methods in Medical Research, pp. 116-126, 147-166. New York: Halsted Press, John Wiley \& Sons Inc.

Briend, A. (1985). Do maternal energy reserves limit fetal growth? Lancet i, 138-140.

Coward, W. A., Paul, A. A. \& Prentice, A. M. (1984). The impact of malnutrition on human lactation: observations from community studies. Federation Proceedings 43, 2432-2437.

Forsum, E., Kabir, N., Sadurskis, A. \& Westerterp, K. (1992). Total energy expenditure of healthy Swedish women during pregnancy and lactation. American Journal of Clinical Nutrition 56, 334-342.

Forsum, E., Sadurskis, A. \& Wager, J. (1988). Resting metabolic rate and body composition of healthy Swedish women during pregnancy. American Journal of Clinical Nutrition 47, 942-947.

Goldberg, G. R., Prentice, A. M., Coward, W. A., Davis, H. L., Murgatroyd, P. R., Sawyer, M. B., Ashford, J. \& Black, A. E. (1991). Longitudinal assessment of the compartments of energy balance in well-nourished lactating women. American Journal of Clinical Nutrition 54, 788-798.

Gonzalez-Cossio, T. \& Delgado, H. (1991). Functional consequences of maternal malnutrition. World Review of Nutrition and Dietetics 64, 139-173.

Hammond, J. (1944). Physiological factors affecting birth weight. Proceedings of the Nutrition Society 2, 8-13.

Hamosh, M., Clary, T. R., Chernich, S. S. \& Scow, R. O. (1970). Lipoprotein lipase activity of adipose and mammary tissue and plasma triglyceride in pregnant and lactating rats. Biochimica et Biophysica Acta 210, $473-482$.

Hytten, F. E. (1980). Weight gain in pregnancy. In Clinical Physiology in Obstetrics, pp. 193-233 [F. E. Hytten and G. Chamberlain, editors]. London: Blackwell Scientific Publications.

Kirk, R. E. (1966). Experimental design. In Procedures for the Behavioral Science, pp. 179-184. Belmont: Wadsworth Publishing Company, Inc.

Knopp, R. H., Sandek, C. D., Arky, R. A. \& O'Sullivan, J. B. (1973). Two phases of adipose tissue metabolism in pregnancy: maternal adaptation for fetal growth. Endocrinology 92, 984-988.

Langhoff-Roos, J., Lindmark, G. \& Gebre-Medhin, M. (1987). Maternal fat stores and fat accretion during pregnancy in relation to infant birthweight. British Journal of Obstetrics and Gynaecology 94, 1170-1177.

Lederman, S. A. \& Rosso, P. (1981). Effects of obesity, food restriction and pregnancy on fetal and maternal weight and body composition in rats. Journal of Nutrition 111, 2162-2171.

Naismith, D. J., Richardson, D. P. \& Pritchard, A. E. (1982). The utilization of protein and energy during lactation in the rat, with particular regard to the use of fat accumulated in pregnancy. British Journal of Nutrition 48, 433-441.

Rebuffe-Scrive, M., Enk, L., Crona, N., Lönnroth, P., Abrahamsson, L., Smith, U. \& Björntorp, P. (1985). Fat cell metabolism in different regions in women. Effect of menstrual cycle, pregnancy and lactation. Journal of Clinical Investigation 75, 1973-1976.

Sadurskis, A., Kabir, N., Wager, J. \& Forsum, E. (1988). Energy metabolism, body composition, and milk production in healthy Swedish women during lactation. American Journal of Clinical Nutrition 48, 4449.

Sadurskis, A., Sohlström, A., Kabir, N. \& Forsum, E. (1991). Energy restriction and the partitioning of energy between the costs of reproduction in rats in relation to growth of the progeny. Journal of Nutrition 121, $1798-1810$. 
Snedecor, G. W. \& Cochran, W. G. (1973). Statistical Methods, pp. 272-275, 299-338. Ames, IA: Iowa State University Press.

Spray, C. M. (1950). A study of some aspects of reproduction by means of chemical analysis. British Journal of Nutrition 4, 354-360.

Steingrimsdottir, L., Greenwood, M. R. C. \& Brasel, J. A. (1980). Effect of pregnancy, lactation and a high-fat diet on adipose tissue of Osborne-Mendel rats. Journal of Nutrition 110, 600-609.

Stini, W. A. (1978). Early nutrition, growth, disease and human longevity. Nutrition and Cancer 1, 31-39.

Willett, W. (1989). The search for the causes of breast and colon cancer. Nature 338, 389-394.

World Health Organization (1985). Energy and Protein Requirements. Technical Report Series no. 724. Geneva: WHO.

Young, M. C. \& Rasmussen, K. M. (1985). Effect of varying degrees of chronic dietary restriction in rat dams on reproductive and lactational performance and body composition in dams and their pups. American Journal of Clinical Nutrition 41, 979-987. 